The mean duration in days of fever after the start of treatment was 5.4 (S.D. \pm 3.2 ) in group $A$ and 3.9 (S.D. \pm 1.7 ) in group B, with ranges of 1-15 and 1-9 days respectively. The difference is statistically significant $(t=3.087 ; \mathrm{P}<0.05)$. The mean lengths of the febrile period in the two groups are compared in Fig. 1. The daily percentage of patients in each group without fever is shown in Fig. 2. The difference is statistically significant at the fifth, sixth, and seventh days.

The biological characteristics, phage type, biochemical type, and minimal inhibitory concentration of chloramphenicol and ampicillin for the 35 strains of salmonella recovered from 31 patients in group $A$ and for the 61 strains from 43 patients in group $B$ are given in the Table. As can be seen, they were mostly phage type A.

Biological Characteristics of Strains of Salm. typhi Isolated from Blood or of Faeces of Patients with Typhoid Fever

\begin{tabular}{|c|c|c|c|c|c|c|}
\hline \multirow{2}{*}{$\begin{array}{l}\text { Treatment } \\
\text { Group }\end{array}$} & \multirow{2}{*}{$\begin{array}{c}\text { No. of } \\
\text { Strains } \\
\text { Isolated* }\end{array}$} & \multicolumn{2}{|c|}{$\begin{array}{c}\text { Minimum Inhibitory } \\
\text { Concentration } \\
(\mu \mathrm{g} / \mathrm{ml})\end{array}$} & \multirow{2}{*}{$\begin{array}{c}\text { Phage Type } \\
(\%)\end{array}$} & \multicolumn{2}{|c|}{$\begin{array}{c}\text { Biochemical Type } \\
(\%)\end{array}$} \\
\hline & & $\begin{array}{l}\text { Ampi- } \\
\text { cillin }\end{array}$ & $\begin{array}{l}\text { Chloram- } \\
\text { phenicol }\end{array}$ & & I & II \\
\hline $\mathbf{A}$ & $35 \dagger$ & $\leqslant 0.4$ & $\leqslant 4$ & $\left\{\begin{array}{lr}\mathrm{A}_{1} & 85 \cdot 7 \\
\mathrm{D}_{1} & 5 \cdot 7 \\
\mathrm{C}_{4} & 5 \cdot 7 \\
\mathrm{~B}_{2} & 2.9\end{array}\right\}$ & $97 \cdot 2$ & $2 \cdot 8$ \\
\hline B & $61 \ddagger$ & $\leqslant 0.4$ & $\leqslant 4$ & $\left\{\begin{array}{lr}\mathrm{A}_{1} & 91.8 \\
\mathrm{D}_{1} & 4.9 \\
\mathrm{~F}_{4} & 1.6 \\
\text { NT } & 1.6\end{array}\right\}$ & $88 \cdot 6$ & 11.4 \\
\hline
\end{tabular}

* In some patients Salm typhi was isolated from both blood and faeces. † Isolated from 31 patients.

Isolated from 43 patients.

Biochemical type according to Christensen (1938): I = xylose +, arabinose -; II $=$ xylose - , arabinose - .
Because of the susceptibility of all the strains of salmonella to either antibiotic, a comparison of their susceptibility to the combined antibiotics with their susceptibility to each antibiotic separately was impracticable. Such a comparison would be possible only after inducing a state of relative resistance to either antibiotic, thus making determination of susceptibility to the combination more meaningful. This work is in progress.

No carriers of Salm. typhi were found in cultures of faeces from patients in either group 30 to 45 days after defervescence.

\section{Conclusion}

Treatment of typhoid fever with combined chloramphenicol and ampicillin shortened the febrile period after the start of therapy by up to $29 \%$ compared with patients treated with chloramphenicol alone. The difference was statistically significant. The standard deviation of the mean of the length of the febrile periods from the start of treatment was significantly smaller for patients in group B than for those in group A. Ranges were also narrower for group B (1-9 days) than for group A (1-15 days). No febrile relapses were observed in group B but there were two in group A.

Chloramphenicol and ampicillin combined, therefore, seem to be better than chloramphenicol alone in the treatment of typhoid fever.

\section{Reference}

Christensen, M. (1938). Fournal of Hygiene, 38, 688.

\title{
Nomograms for Calculation of Oxygen Consumption and Respiratory Exchange Ratio
}

\author{
J. F. NUNN
}

British Medical fournal, 1972, 4, 18-20

\section{Introduction}

Measurement of oxygen consumption by determination of the composition and volume of expired air (the Douglas bag method)

\section{Summary}

Nomograms have been prepared whereby the respiratory exchange ratio may be derived from the concentrations of carbon dioxide and oxygen in expired gas and oxygen consumption from the volume and oxygen concentration of expired gas; they apply only to patients breathing room air. The nomogram for the respiratory exchange ratio has an error of less than 0.01 , which is the limit of visual discrimination on the nomogram. The nomogram for oxygen consumption has an error of standard deviation $7.73 \mathrm{ml} / \mathrm{min}$. This error may be substantially reduced by excluding cases with a respiratory exchange ratio outside the range $0 \cdot 70-0 \cdot 93$. Under these conditions the maximum error was $10 \mathrm{ml} / \mathrm{min}$, which is acceptable for a wide range of clinical purposes.

\footnotetext{
Division of Anaesthesia, Clinical Research Centre, Harrow, Middlesex

J. F. NUNN, M.D., PH.D., F.F.A. R.c.s., Head of Division
} is much more accurate than the closed circuit spirometrict echnique, and is also much more convenient when combined with the measurement of such respiratory parameters as physiological dead space and pulmonary venous admixture. The method thus has much to commend it for routine use in departments concerned with lung function.

Calculation of oxygen consumption $\left(\dot{\mathrm{V}}_{2}\right)$ is usually based on the following equation when the inspired gas is room air:

$$
\begin{aligned}
& \dot{\mathrm{VO}}{ }_{2}(\mathrm{ml} / \mathrm{min})=\frac{\text { Volume collected }(1 .)}{\text { Collection time }(\mathrm{min})} \\
& \times \mathrm{f}\left(\frac{0.2093\left(1-\mathrm{F}_{\bar{E} O_{2}}-\mathrm{FECO}_{2}\right)}{0.7904}\right)-\mathrm{F}_{\bar{E} O_{2}} \quad \ldots
\end{aligned}
$$

where $f=$ the factor required to convert gas volumes measured at ambient temperature and pressure saturated (ATPS) to the equivalent volume under conditions of standard temperature and pressure dry (STPD), $\mathrm{F}_{\overline{\mathrm{EO}}} \mathrm{O}_{2}=$ oxygen concentration in mixed expired gas, and $\mathrm{FECO}_{2}=$ carbon dioxide concentration in mixed expired gas (Pappenheimer et al., 1950).

Solution of this equation is easy with a programmable calculating machine but is tedious when manual methods are used. We have therefore considered the magnitude of the error 
introduced when a simplified equation of the following type is used:

$$
\dot{\mathrm{VO}}_{2}=\frac{\text { Volume collected }}{\text { Collection time }} \times \mathrm{F}\left(20.93-\mathrm{FEO}_{2}{ }^{*}\right) \ldots
$$

where $\mathrm{F}$ is a factor empirically derived from trial calculations to give the minimum error when $\dot{\mathrm{Vo}}_{2}$ is compared with values derived from equation (i). Much the largest source of error is variations in the respiratory exchange ratio, in comparison with which variations in barometric pressure and room temperature are of little importance.

Two nomograms have been prepared. One corresponds to equation (ii) and is intended for calculation of oxygen consumption. With the second the respiratory exchange ratio is derived from the ratio of $\mathrm{FECO}_{2}$ to the difference between the oxygen concentrations in room air and mixed expired gas $\left(20.93-\mathrm{FEO}_{2}\right)$. Satisfactory results may be obtained with a quadratic expression as follows:

respiratory exchange ratio $=$

$$
a\left(\frac{\mathrm{FECO}_{2}}{20.93-\mathrm{FE}_{2}{ }^{2}}\right)^{2}+b\left(\frac{\mathrm{FE}^{2} \mathrm{CO}_{2}}{20 \cdot 93-\mathrm{FEO}_{2}}\right)
$$

\section{Construction of Nomograms}

Optimal values for the factors $F$ in equation (ii) and $a$ and $b$ in equation (iii) were derived from trial calculations, using data for the following variables measured in 30 consecutive clinical studies: barometric pressure (at altitude of 200 feet $(60.96 \mathrm{~m})$ above sea level); room temperature; volume of expired gas collected; duration of collection; $\mathrm{FCE}_{2}$; and $\mathrm{FEO}_{2}$.

The clinical studies were carried out on patients breathing air and either resting or exercising at low power levels. The accuracy of the primary measurements is not relevant to the present purpose since the values were used only to provide a typical series of measurements which might be expected in this type of study.

Nomograms were then constructed to solve equations (ii) and (iii) (Fig. 1). The $\mathrm{F}_{\overline{\mathrm{EO}}}$, scale is common to both. The respiratory exchange ratio is derived from the centre and left-

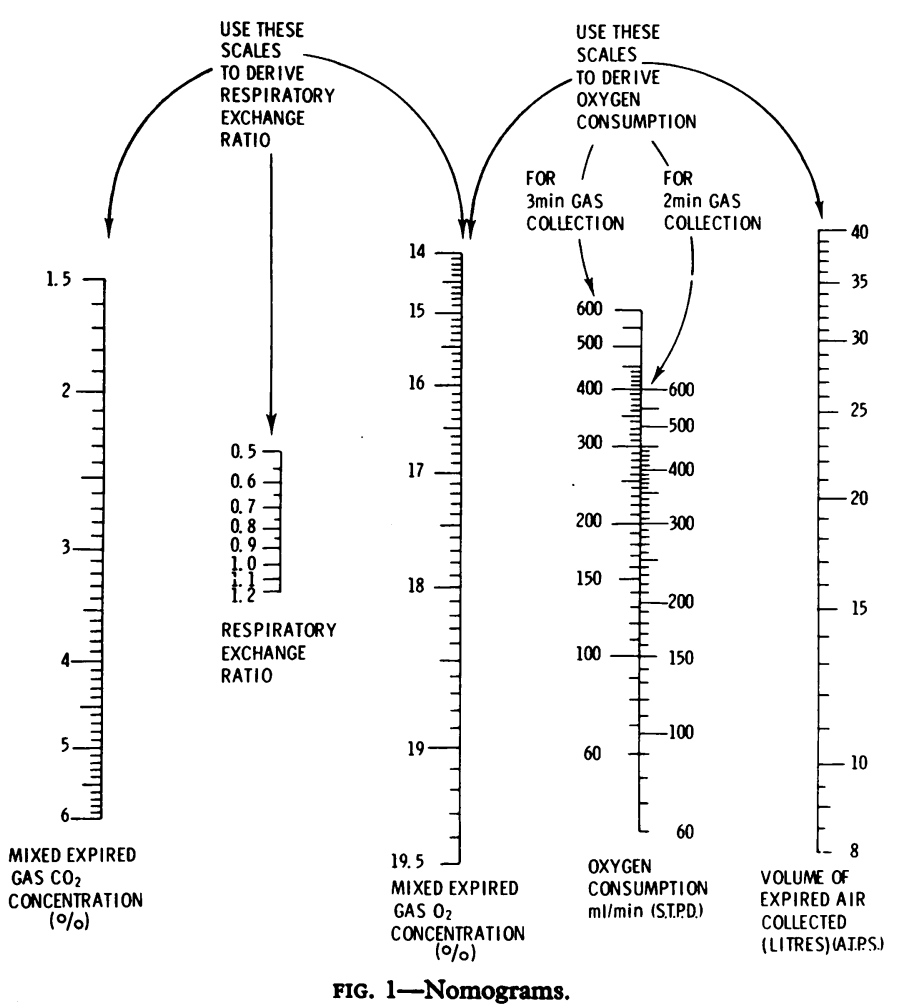

*For convenience gas concentrations are expressed as percentages in equations (ii) and (iii). hand scales and the oxygen consumption from the centre and right-hand scales. There is provision for two- and three-minute gas collection periods. The factor for conversion of gas volumes from ATPS to STPD is included in the nomograms.

Optimal values for the factors were as follows: $F=0.924$, $a=0.249, b=0.750$, these values being obtained under the conditions shown in the Table.

Values for Variables for which Optimal Values for Factors $F, a$, and $b$ in the

\begin{tabular}{|c|c|c|}
\hline Variable & Mean \pm S.D. & Range \\
\hline $\begin{array}{l}\text { Barometric pressure (mm } \mathrm{Hg}) \\
\left.\text { Room temperature ( }{ }^{\circ} \mathrm{C}\right) \\
\text { Conversion factor ATPS to STPD } \\
\text { Respiratory exchange ratio } \\
\text { Oxygen consumption (ml/min) }\end{array}$ & $\begin{array}{l}752 \pm 12 \cdot 0 \\
21 \cdot 8 \pm 1 \cdot 3 \\
0 \cdot 892 \pm 0 \cdot 0150 \\
0 \cdot 840 \pm 0 \cdot 114 \\
270 \cdot 2 \pm 114 \cdot 8\end{array}$ & $\begin{array}{c}731-772 \\
19 \cdot 0-25 \cdot 0 \\
0 \cdot 870-0 \cdot 914 \\
0 \cdot 611-1 \cdot 026 \\
133-641\end{array}$ \\
\hline
\end{tabular}
Nomograms were Calculated

\section{Accuracy of Calculation with Nomograms}

\section{RESPIRATORY EXCHANGE RATIO}

Equation (iii) gave a mean value for the respiratory exchange ratio which agreed with the mean of the values calculated by the customary equation to three significant figures. The individual discrepancies all lay within \pm 0.002 . Clearly this accuracy is beyond the visual discrimination which is possible when using the nomogram, which can be read only to 0.01 with confidence.

\section{OXYGEN CONSUMPTION}

The mean oxygen consumption for the series derived from the nomogram agreed with the calculated value to three significant figures. The standard deviation of the difference was $7.73 \mathrm{ml} /$ min. The error did not appear to be a function of the actual oxygen consumption (Fig. 2) but was related to the respiratory exchange ratio (Fig. 3). The nomogram for derivation of the

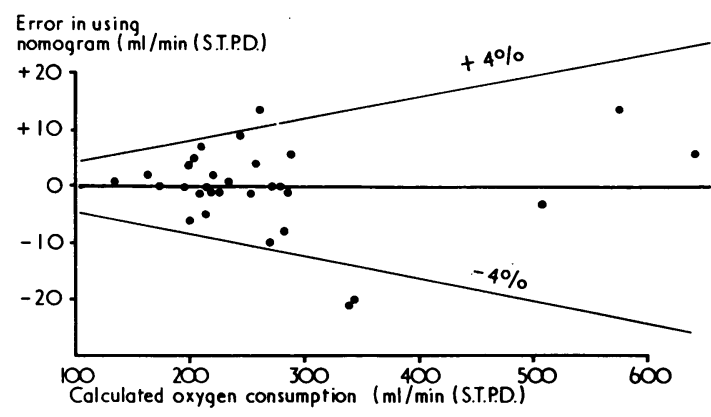

FIG. 2-Error in derived oxygen consumption (nomogram value-calculated value) plotted against oxygen consumption.

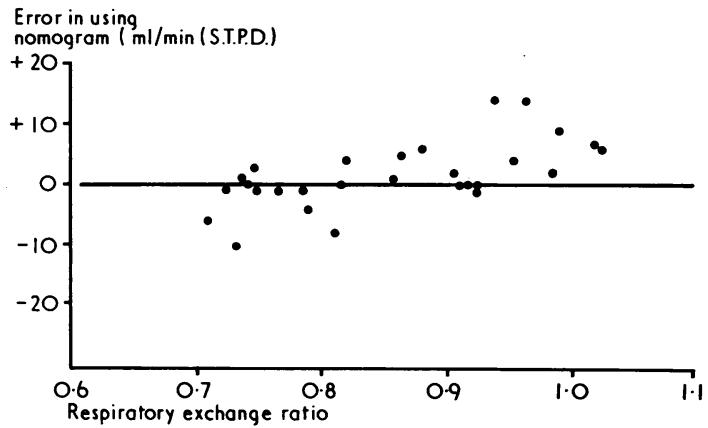

FIG. 3-Error in derived oxygen consumption (nomogram value-calculated value) plotted against respiratory exchange ratio. 
respiratory exchange ratio may be used to determine whether the ratio is outside the normal range (usually owing to an unsteady respiratory state), and in such cases it would be preferable to use equation (i) rather than to rely on the nomogram for measurement of oxygen consumption. When the respiratory exchange ratio was within the limits $0.70-0.93$ the maximum error was $10 \mathrm{ml} / \mathrm{min}$ (S.D. 3.92).

\section{Discussion}

The respiratory exchange ratio can be derived from the nomogram with an error which is limited by visual discrimination on the nomogram. With normal eyesight it should be possible to be accurate within 0.01 , which is sufficient for many purposes. It is certainly adequate for determining whether the value is sufficiently far from the normal range to invalidate the derivation of oxygen consumption on the other half of the nomogram.

Oxygen consumption may be derived from the volume and oxygen concentration of expired air with an error of standard deviation $7.73 \mathrm{ml} / \mathrm{min}$, the error compounding variations in respiratory exchange ratio, barometric pressure, and laboratory temperature. When patients with abnormal values for respiratory exchange ratio are excluded the error is substantially less, and acceptable for a wide range of clinical purposes. Both nomograms apply only to patients breathing room air.

\section{Reference}

Pappenheimer, J. R., et al. Federation Proceedings, 9, 602.

\title{
Nomograms for Calculation of Heat Loss
}

\author{
FRANK HOUSE, RAYMOND VALE
}

British Medical fournal, 1972, 4, 20-21

\section{Summary}

Two nomograms are presented. The first enables the mean surface and body temperatures and the body heat content of a patient of given weight to be determined from measurements of skin temperature at three sites and of the core (rectal) temperature. The second enables the change in heat content of such a patient to be determined from the change in mean body temperature.

\section{Introduction}

Heat production and loss from the body can be measured directly by calorimetry and indirectly by measuring the temperature at various sites on the body surface. The first method is too difficult for clinical use, but the latcer is possible and useful in many circumstances. Changes in rectal temperature alone do not adequately explain discrepancies between heat production and heat loss. Heat debt calculated from the mean surface temperature "mixed" with rectal temperature was found by Burton and Edholm (1955) to give the best agreement with observed differences between heat production and heat loss. They found that the best value for the mixing coefficient was:

$$
\theta=\left(0.7 \times \mathrm{T}_{\text {core }}\right)+\left(0.3 \times \mathrm{T}_{\mathrm{S}}\right)
$$

where $\theta$ represents the mean body temperature, $T_{\text {core the }}$ core (rectal) temperature, ard $T_{S}$ the mean surface temperature.

The mean surface temperature is derived as follows:

$\mathbf{T}_{\mathbf{S}}=\left(0.14 \times \mathrm{T}_{\text {forearm }}\right)+\left(0.36 \times \mathrm{T}_{\text {calf }}\right)+\left(0.5 \times \mathrm{T}_{\text {abdomen }}\right)$ these temperatures being measured on the skin surface at these sites.

If heat balance is the point where heat production equals heat loss then:

$$
\Delta \text { heat balance }=\Delta \theta \times 0.83 \times \text { wt. }
$$

Guy's Hospital Medical School and Guy's Hospital, London S.E.1 FRANK HOUSE, M.SC., Lecturer in Pharmacology

RAYMOND VALE, F.R.C.P. (Ed.), F.F.A. R.C.S., Consultant Anaesthetist where $\Delta$ heat balance $=$ change in heat balance, $\Delta \theta=$ change in mean body temperature, $0.83=$ specific heat of tissues, and wt. = body weight $(\mathrm{kg})$.

Calculating these values arithmetically is laborious, and for use in clinical practice two nomograms have been devised.

\section{Nomogram 1}

A straight edge is laid across scale A and scale C (Fig. 1) at the measured temperatures of the skin of the calf and the skin of the forearm. The point of intersection on scale $B$ is joined to the abdominal skin temperature on scale $\mathrm{D}$ and the mean surface temperature is read on scale $\mathrm{C}$. The mean surface temperature on scale $\mathrm{C}$ is then joined to the core temperature on scale $\mathrm{E}$ and the point of intersection of this line on scale $D$ gives the mean body temperature. If this point is joined to the body weight on scales F1, F2, or F3 the heat content can be read on the corresponding scale (G1, G2, or $\mathrm{G} 3$ ).

\section{Nomogram 2 (Fig. 2)}

Often it is only changes in heat content that are of interest. In such cases it may prove more convenient to use nomogram 1 to obtain mean body temperature at various times and then nomogram 2 to convert changes in temperature to changes in heat content. If the body weight on the first scale of nomogram 2 is joined to the change in mean body temperature on the third scale, the change in heat content can be read from the point of intersection on the second scale. For small body weights the two scales on the right of the nomogram are used.

\section{Example of Use}

The three sets of temperatures in the Table can be used to illustrate the use of the nomograms.

The mean surface temperature derived from the preinduction temperatures by means of nomogram 1 is $31.8^{\circ} \mathrm{C}$ and the mean body temperature is $35.0^{\circ} \mathrm{C}$. Repeating the procedure with the postinduction temperatures (measured 15 minutes after the induction of anaesthesia) gives a mean surface temperature of 